\title{
Influencia de la Dentina en el Efecto Antibacteriano de 2 Concentraciones de Hipoclorito de Sodio en el Crecimiento de Enterococcus faecalis ATCC 29212
}

\author{
Influence of the Dentin on the Antibacterial Effect of 2 Concentrations of \\ Sodium Hypochlorite in the Growth of Enterococcus faecalis ATCC 29212
}

\author{
Samantha Martínez Oroscoํ; Solange Mendoza Rodrigo² \& Aurealuz Morales Guevara ${ }^{3}$
}

\begin{abstract}
MARTíNEZ, O. S.; MENDOZA, R. S. \& MORALES, G. A. Influencia de la dentina en el efecto antibacteriano de 2 concentraciones de Hipoclorito de Sodio en el crecimiento de Enterococcus faecalis ATCC 29212. Int. J. Odontostomat., 14(3):367372, 2020.

RESUMEN: Este estudio in vitro evaluó la influencia de la dentina sobre el efecto antibacteriano contra Enterococcus faecalis ATCC 29212 de dos concentraciones de Hipoclorito de Sodio ( $\mathrm{NaOCl}$ ) 2,5 \% y $5 \%$. Se empleó polvo de dentina a partir de dientes humanos $(84 \mu \mathrm{g} / \mathrm{ml})$ y la supervivencia de la bacteria se evaluó realizando recuento de unidades formadoras de colonias (UFC) a los 10, 30 y 60 segundos. Los datos se analizaron con la prueba estadísticaANOVA factorial no encontrándose diferencias estadísticamente significativas entre los grupos con dentina y sin dentina. En conclusión, la dentina en este estudio no influyó en el efecto antibacteriano del Hipoclorito de Sodio en ninguna concentración, ni en los tiempos.
\end{abstract}

PALABRAS CLAVE: dentina, hipoclorito de sodio, Enterococcus faecalis.

\section{INTRODUCCIÓN}

Se ha aceptado durante muchos años que los microorganismos son el principal agente etiológico de la patología pulpar y periapical, siendo la persistencia de éstos la principal causa del fracaso del tratamiento Endodóntico (Kakehashi et al., 1965). Estudios han demostrado que al menos algunas especies microbianas pueden invadir profundamente la dentina en condiciones relativamente favorables (Macedo et al., 2015). La microbiota presente en los dientes donde el tratamiento endodóntico fracasó, es predominantemente anaerobia facultativa y Gram positiva, siendo el Enterococcus faecalis la especie que se aísla con mayor frecuencia (Stuart et al., 2006).

La preparación biomecánica es imprescindible para la eliminación de la estructura dental infectada pero también es necesario desinfectar los conductos radiculares con medios químicos (Arias-Moliz et al., 2016)

Según Zehnder et al. (2015), el irrigante ideal del conducto radicular debe tener un amplio espectro antimicrobiano, disolver el tejido necrótico de la pulpa, inactivar la endotoxina, prevenir o eliminar la capa de frotis, ser no tóxico y no cáustico para los tejidos periodontales. Aunque $\mathrm{NaOCl}$ no cumple plenamente con su descripción de un irrigante ideal, cumple con muchos de sus requisitos, además de tener propiedades antibacterianas, es fácilmente disponible, bajo costo y tiene una larga vida útil (Macedo et al., 2014), por ello sigue siendo el irrigante de elección, debido además a su capacidad para disolver tejido orgánico y su acción contra los microorganismos, pero es incapaz de eliminar la capa de frotis para evitar la acumulación de restos de tejido duro (Arias-Moliz et al., 2014).

Áreas complejas o la presencia de un ambiente químico complejo que contiene productos orgánicos e inorgánicos, como la pulpa necrótica, residuos dentinarios y biofilms pueden estar relacionados con el fracaso del irrigante. Diferentes agentes desinfectantes muestran diferente sensibilidad a la acción de los diversos inactivadores potenciales, como la denti-

\footnotetext{
${ }^{1}$ Universidad Católica Santo Toribio de Mogrovejo, Chiclayo-Perú.

2 Universidad Católica Santo Toribio de Mogrovejo, Chiclayo-Perú.

${ }^{3}$ Docente de la cátedra de Endodoncia de la Universidad Católica Santo Toribio de Mogrovejo- Chiclayo Perú.
} 
na, las proteínas séricas, la hidroxiapatita, el colágeno derivado de diferentes fuentes y la biomasa microbiana (Haapasalo et al., 2000).

Los componentes de los residuos de dentina pueden actuar como una barrera que disminuye la actividad antimicrobiana del $\mathrm{NaOCl}$, dado que este reacciona con la materia orgánica e inorgánica, lo que resulta en una pérdida de su cloro disponible, causando la desgasificación de la solución, degradación de la proteína, además de un aumento de la temperatura y cambios en el nivel de $\mathrm{pH}$ (Christensen et al., 2008).

Se propone que los materiales orgánicos, como los componentes de la dentina o restos de tejidos, pueden interactuar con los irrigantes, y ésta interacción de sustrato inhibe competitivamente la reacción entre el irrigante y las bacterias. Por esta razón, es posible que tener más substrato orgánico interactuando con la solución de riego puede retrasar inherentemente la eliminación de bacterias (Christensen et al.).

Estudios realizados demostraron que el colágeno tipo I y el glicosaminoglicano de la dentina perdieron su acción después del tratamiento con $\mathrm{NaOCl}$ cuando se utilizó dentina desmineralizada. Sin embargo, en la dentina intacta este efecto fue mínimo, lo que sugiere que la hidroxiapatita tiene un papel protector por la incorporación de colágeno y otras proteínas contra la actividad oxidativa de $\mathrm{NaOCl}$ (Camps \& Pashley, 2000).

Ante esta condición surge la necesidad de buscar más evidencia científica acerca de ésta inhibición.

El presente estudio tuvo como objetivo evaluar la influencia de la dentina en el efecto antibacteriano de dos concentraciones de Hipoclorito de Sodio en el crecimiento de Enterococcus faecalis ATCC 29212.

\section{MATERIAL Y MÉTODO}

Se realizó un estudio de diseño experimental, con enfoque cuantitativo y según el tipo de investigación analítico. Se evaluaron placas petris con cepa de Enterococcus faecalis ATCC 29212, polvo de dentina, Hipoclorito de Sodio al 2,5 \%, 5 \% y divididas en grupos con dentina y sin dentina.
En esta investigación de tipo experimental in vitro, se consideró los protocolos de bioseguridad para la manipulación de los materiales y soluciones a utilizar en el laboratorio: Cepa de Enterococcus faecalis ATCC 29212, Hipoclorito de Sodio y dentina en polvo y no se realizó ninguna prueba directa en humanos y/o animales.

Para obtener el polvo de dentina se recolectaron premolares humanos que cumplan con los siguientes criterios de inclusión: extraídos por motivos ortodónticos, periodo máximo desde su extracción 15 días, almacenados en cloruro de sodio desde su extracción y donados voluntariamente por clínicas o consultorios odontológicos, en cuanto a los criterios de exclusión: premolares con lesión cariosa y ápices abiertos. Posterior a la selección de los premolares, se les retiró la pulpa dental y el cemento con fresas diamentadas de grano fino, las piezas dentales se trituraron utilizando un molino modelo IKA A11 y se autoclavaron (Morgental et al., 2013).

Para evaluar la actividad antibacteriana sin polvo de dentina se trabajó con 2 microtubos y se les denominó primer y segundo tratamiento. El primer microtubo con el primer tratamiento consistió en 150 ul de Hipoclorito de Sodio al 2,5\% y 150 ul de agua destilada. Se le añadió 150 ul de suspensión bacteriana previamente tratada y desde el momento en que ésta hizo contacto con la solución homogenizada de Hipoclorito de Sodio y agua destilada se contabilizó los 10,30 y 60 segundos. Se hicieron diluciones seriadas hasta 10-3. Los 3 tubos en la dilución de series; contenían el inactivador tiosulfato de sodio al 0,5 $\%$ que reduce el efecto remanente del Hipoclorito de Sodio. Se extrajeron 100 ul de la última dilución, se cultivaron en placas petris con agar $\mathrm{BHI}$ correctamente rotuladas y se incubaron a $37^{\circ} \mathrm{C}$.

En el segundo microtubo con el segundo tratamiento se repitió el procedimiento previamente explicado, con la diferencia de que se utilizó Hipoclorito de Sodio al $5 \%$. Se contaron las colonias bacterianas después de 24 horas. Ambos tratamientos se realizaron por quintuplicado (Fig. 1).

Con respecto a la inhibición de la actividad antibacteriana por polvo de dentina se trabajó con 2 microtubos más y se les denominó tercer y cuarto tratamiento. En el tercer microtubo con el tercer tratamiento se utilizó 150 ul de Hipoclorito de Sodio al $2,5 \%$ y 150 ul de agua destilada con $84 \mathrm{mg}$ de dentina. Se le añadió 150 ul de suspensión bacteriana 


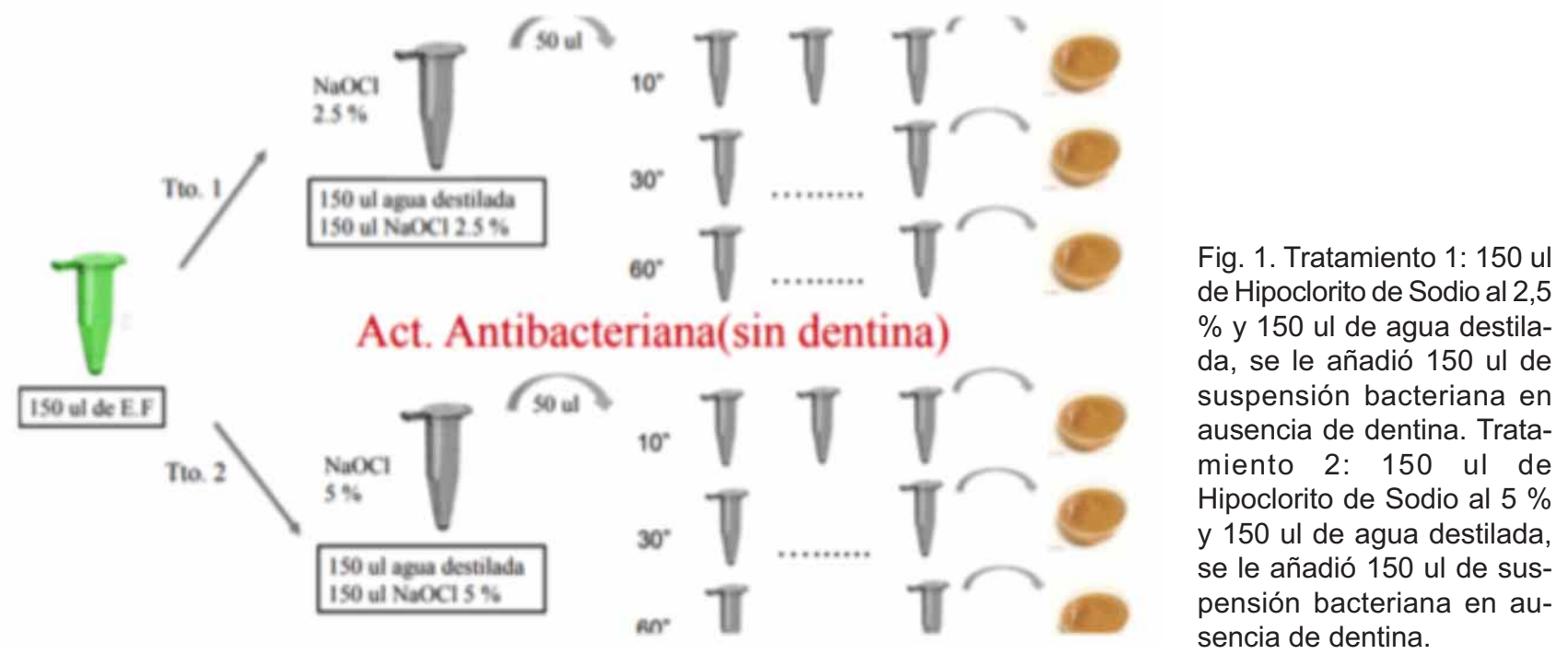

previamente tratada y desde el momento en que ésta hizo contacto con la solución homogenizada de Hipoclorito de Sodio y agua destilada se contabilizó los 10,30 y 60 segundos. Se hicieron diluciones seriadas hasta 10-3. Los 3 tubos, en la dilución de series; contenían el mismo inactivador: tiosulfato de sodio al $0,5 \%$. Se extrajeron 100 ul de la última dilución, se cultivaron en placas petris con agar $\mathrm{BHI}$ correctamente rotuladas y se incubaron a $37^{\circ} \mathrm{C}$. En el cuarto microtubo con el cuarto tratamiento se repitió el procedimiento previamente explicado, con la diferencia de que se utilizó Hipoclorito de Sodio al $5 \%$. Se contaron las colonias bacterianas después de 24 horas. Ambos tratamientos se realizaron por quintuplicado (Fig. 2).

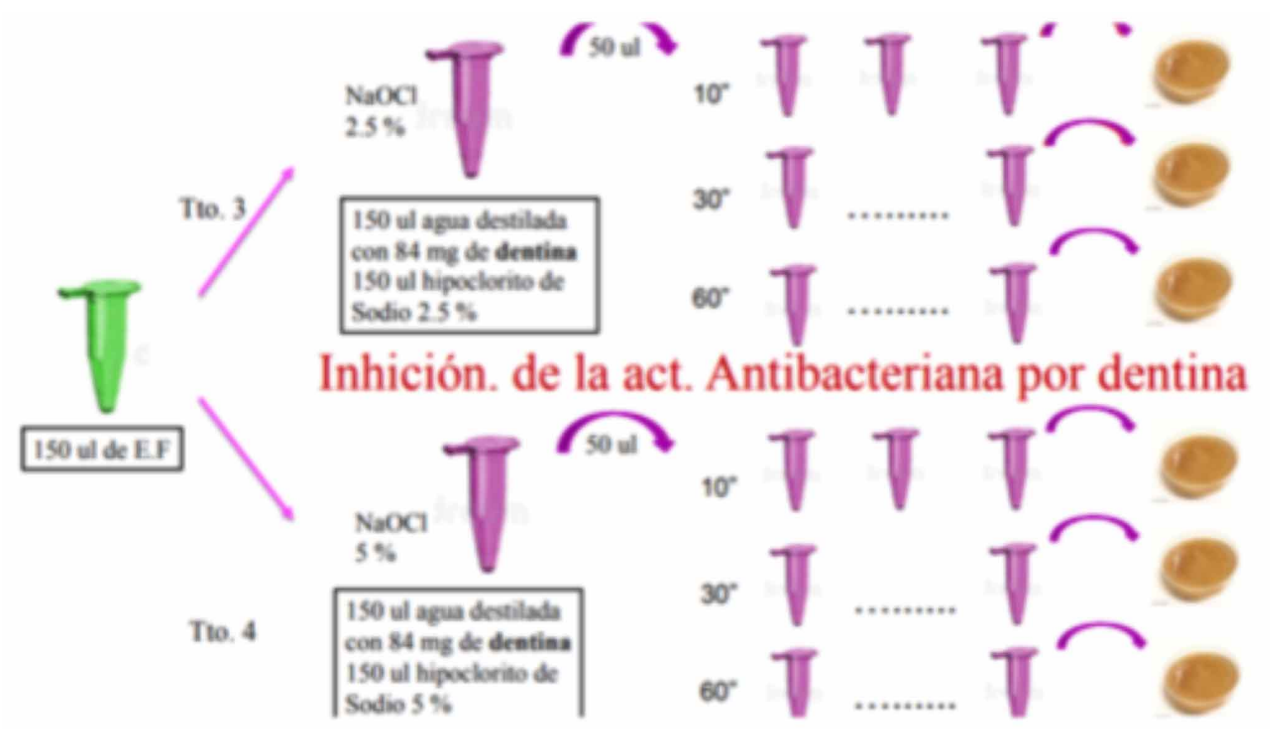

Fig. 2. Tratamiento 3: $150 \mathrm{ul}$ de Hipoclorito de Sodio al 2,5 $\%$ y 150 ul de agua destilada con $84 \mathrm{mg}$ de dentina, se le añadió $150 \mathrm{ul}$ de suspensión bacteriana. Tratamiento 4: 150 ul de Hipoclorito de Sodio al $5 \%$ y $150 \mathrm{ul} \mathrm{de}$ agua destilada con $84 \mathrm{mg}$ de dentina, se le añadió 150 ul de suspensión bacteriana. 


\section{RESULTADOS}

Se observó la supervivencia del microrganismo a través de unidades formadoras de colonias (UFC) y se realizaron las anotaciones correspondientes en la ficha de recolección de datos.

Al evaluar los grupos sin dentina y con dentina con ambas concentraciones de Hipoclorito de Sodio y en todos los tiempos determinados no se encontró diferencia estadísticamente significativa aplicando la prueba estadística Anova Factorial para muestras independientes obteniendo un p-valor de 0,533 (Tabla I). La muerte del microorganismo en todos los tratamientos fue casi al $100 \%$.

Tabla I. Evaluación de la influencia de la dentina en el efecto antibacteriano de dos concentraciones de Hipoclorito de Sodio en el crecimiento de Enterococcus faecalis ATCC 29212.

\begin{tabular}{ccccc}
\hline & \multicolumn{2}{c}{ Sin dentina } & \multicolumn{2}{c}{ Con dentina } \\
\hline & $\begin{array}{c}\text { Hipoclorito de } \\
\text { sodio al 2,5 \% }\end{array}$ & $\begin{array}{c}\text { Hipoclonito de sodio } \\
\text { al 5 \% }\end{array}$ & $\begin{array}{c}\text { Hipoclorito de } \\
\text { sodio al 2,5\% }\end{array}$ & $\begin{array}{c}\text { Hipoclorito de sodio } \\
\text { al 5 \% }\end{array}$ \\
\hline $10 "$ & $99,99120 \%$ & $99,99760 \%$ & $99,99200 \%$ & $99,99660 \%$ \\
$30 "$ & $99,99560 \%$ & $99,99940 \%$ & $99,99660 \%$ & $99,99980 \%$ \\
$60 "$ & $99,99760 \%$ & $99,99960 \%$ & $99,99760 \%$ & $99,99980 \%$ \\
\hline \multicolumn{5}{c}{$p 0,533^{*}$} \\
\hline
\end{tabular}

${ }^{*}$ Anova Factorial.

\section{DISCUSIÓN}

Dentro del sistema del canal radicular, el $\mathrm{NaOCl}$ reacciona con la materia orgánica e inorgánica, lo que resulta en una pérdida de su cloro disponible ya sea por la reacción con contenido orgánico de la dentina, reacción de la pulpa residual, los deshechos y /o sangre, reacción con el material del instrumento activado y la activación, lo que provoca la desgasificación de la solución (Perez et al., 1996).

Al estudiar esta reacción del $\mathrm{NaOCl}$ en presencia de dentina del canal radicular, la eficacia química y el porcentaje de perdida de cloro, son variables importantes. Esta reacción del $\mathrm{NaOCl}$ junto con la capacidad de disolución en los tejidos se ven influenciados por varios parámetros como: tiempo de exposición, área de contacto, temperatura, interacción con otros productos químicos y nivel de $\mathrm{pH}$ (Arias-Moliz et al., 2014).

A partir de ello, en este estudio se evaluó la influencia de la dentina en el efecto antibacteriano del Hipoclorito de Sodio al 2,5\% y $5 \%$ en el crecimiento de Enterococcus faecalis ATCC 29212 a los 10, 30 y 60 segundos.

Se utilizó dentina en polvo al igual que en estudios in vitro anteriores (Haapasalo et al., 2007) debido a que una sustancia pulverizada o con un gran estado de división tiene una mayor velocidad de reacción ya que existe más área de contacto, y por tanto mayor facilidad de colisión entre partículas (White et al., 1994), siendo diferente a las condiciones de la cavidad oral.

Portenier et al. (2002) estudiaron el efecto inhibidor potencial de la matriz dentinaria bovina (colágeno), el polvo de dentina desmineralizada (tratado con EDTA o ácido cítrico) y el colágeno de la piel sobre la actividad antibacteriana de $0,1 \% \mathrm{NaOCl}$ y $0,1 \% / 0,2 \%$ IKI. La matriz de dentina (3\% p / v), que es principalmente colágeno dentinario purificado, era un potente inhibidor de $\mathrm{NaOCl}$ e IKI, con la mayoría de las células de $\mathrm{E}$. faecalis sobreviviendo después de 24 horas de incubación con los medicamentos en las concentraciones dadas. Las propiedades orgánicas de la dentina se alteran en diversas condiciones de esterilización (Portenier et al., 2002).

En el año 2006, Portenier et al. (2006) realizaron otro estudio cuyo objetivo fue investigar la actividad antibacteriana de MTAD (mezcla de isómero de tetraciclina, ácido y detergente) y clorhexidina con o sin cetrimida hacia dos cepas de Enterococcus faecalis y los efectos inhibidores de la dentina y la albúmina sérica bovina sobre dicha actividad. La concentracio- 
nes probadas fueron $\operatorname{MTAD}(100,10$ y $1 \%) ; \operatorname{CHX}(0,2$, $0,02$ y $0,01 \%)$; combinación CHX / CTR $(0,1,0,01$ y $0,01 \%)$. Las sustancias probadas para la inhibición de la actividad antibacteriana de los medicamentos fueron polvo de dentina y BSA (Albumina sérica bovina). Las muestras dieron como resultado que en concentración completa de MTAD (100 \%) y CHX (0,2\%) sin polvo de dentina rápidamente mató por completo a ambas cepas a la hora. El $0,1 \%$ de las células todavía estaban vivas a los 5 minutos en $100 \%$ de MTAD, mientras que $1 \%$ de MTAD y $0,02 \%$ y $0,01 \% \mathrm{CHX}$ no pudo eliminar la bacteria durante la incubación de 1 hora $(65 \%, 0,02 \%$ y $0,01 \%$ supervivencia de la bacteria). Combinando clorhexidina con cetrimida en ambas concentraciones mataron las cepas casi instantáneamente y a los 10 segundos las bacterias ya no podían ser detectadas. MTAD, CHX y la combinación CHX / CTR fueron inhibidos por dentina y BSA a las 24 horas al $100 \%$ en comparación con controles negativos. Por el contrario, la inhibición de $100 \%$ de MTAD (concentración final $33 \%$ ) fue mayor con dentina que con BSA. Con baja MTAD concentraciones de $3,3 \%$, la muerte de $\mathrm{E}$. Faecalis se retrasó mucho o totalmente inhibido por dentina y BSA a las 24 horas (Portenier et al., 2006).

El presente estudio al no encontrar efecto inhibitorio por parte de la dentina frente a la acción del Hipoclorito de Sodio, llevó a conjeturar que se alteraron los componentes orgánicos de la dentina, los cuales son causantes de dicho efecto inhibitorio; debido al método esterilización (autoclave), como lo afirma White et al. quienes investigaron la esterilización de raíces de los dientes enteros usando radiación gamma y esterilización en autoclave de vapor y encontró que el primero no tuvo ningún efecto significativo sobre la estructura de la dentina, mientras que el segundo indujo una pérdida de componentes minerales y de colágeno de la superficie de la muestra (White et al.).

Existen estudios in vitro que hablan sobre varias razones para que el rendimiento in vivo de los irrigantes sea más pobre en comparación con los resultados in vitro. Estos incluyen la penetración deficiente del irrigante, la presencia de un ambiente químico complejo que contiene una mezcla de productos orgánicos e inorgánicos (pulpa necrótica, residuos dentinarios y biofilms), la baja concentración, el tiempo de exposición corto, el volumen, el intercambio deficiente de los irrigantes en las partes apicales del canal de la raíz, la acumulación de residuos de dentina puede influir en la actividad biológica de las soluciones de irrigación (Haapasalo et al., 2007).
Así mismo, es importante tener en cuenta la metodología in vitro aplicada en este estudio. Los resultados relacionados con los procesos de inactivación de las soluciones de riego dentro del sistema de conductos parecen ser diversos y más complejos cuando están presentes diferentes cantidades de desechos y capa de frotis, así como el tejido orgánico, que también influye en la actividad biológica de las soluciones (Haapasalo et al., 2007).

Pocas son las investigaciones que evalúan los inhibidores potenciales como la dentina dentro del canal radicular, el presente estudio puede ser importante para impulsar futuros estudios in vivo donde se asemeje a las condiciones orales.

\section{CONCLUSIONES}

No se encontró diferencia estadísticamente significativa en los grupos con dentina y sin dentina lo que nos lleva a concluir en este estudio que la dentina no influye en el efecto antibacteriano de dos concentraciones de Hipoclorito de Sodio en el crecimiento de Enterococcus faecalis ATCC 29212.

\section{AGRADECIMIENTOS}

A la Universidad Católica Santo Toribio de Mogrovejo, nuestra alma mater, por la formación brindada a lo largo de nuestra carrera.

A la Universidad Nacional de Trujillo por brindarnos facilidades para el uso de su Laboratorio de Biotecnología e Ingeniería Genética y a la Universidad Privada Antenor Orrego por su Laboratorio de Física.

MARTÍNEZ, O. S.; MENDOZA, R. S. \& MORALES, G. A. Influence of the dentin on the antibacterial effect of 2 concentrations of Sodium Hypochlorite in the growth of Enterococcus faecalis ATCC 29212. Int. J. Odontostomat., 14(3):367-372, 2020.

ABSTRACT: This in vitro study evaluated the influence of dentin on the antibacterial effect against Enterococcus faecalis ATCC 29212 of two concentrations of Sodium Hypochlorite $\mathrm{NaOCl} 2.5 \%$ and $5 \%$. Dentin powder was used from human teeth $(84 \mathrm{mg} / \mathrm{ml})$ and the survival of the bacteria was evaluated by counting colony forming units 
(CFU) at 10, 30 and 60 seconds. The data were analyzed with the statistical ANOVA factorial test, finding no statistically significant differences between the groups with and without dentin. In conclusion, the dentin in this study had no inhibitory effect on antibacterial activity of Sodium Hypochlorite and any concentration, nor over time.

KEY WORDS: dentin, sodium hypochlorite, Enterococcus faecalis.

\section{REFERENCIAS BIBLIOGRÁFICAS}

Arias-Moliz, M. T.; Morago, A.; Ordinola-Zapata, R.; Ferrer-Luque, C. M.; Ruiz-Linares, M. \& Baca, P. Effects of dentin debris on the antimicrobial properties of sodium hypochlorite and etidronic acid. J. Endod., 42(5):771-5, 2016.

Arias-Moliz, M. T.; Ordinola-Zapata, R.; Baca, P.; Ruiz-Linares, M. \& Ferrer-Luque, C. M. Antimicrobial activity of a sodium hypochlorite/etidronic acid irrigant solution. J. Endod., 40(12):1999-2002, 2014.

Camps, J. \& Pashley, D. H. Buffering action of human dentin in vitro. J. Adhes. Dent., 2(1):39-50, 2000.

Christensen, C. E.; McNeal, S. F. \& Eleazer, P. Effect of lowering the $\mathrm{pH}$ of sodium hypochlorite on dissolving tissue in vitro. J. Endod., 34(4):449-52, 2008.

Haapasalo, H. K.; Sirén, E. K.; Waltimo, T. M.; Ørstavik, D. \& Haapasalo, M. P. Inactivation of local root canal medicaments by dentine: an in vitro study. Int. Endod. J., 33(2):126-31, 2000.

Haapasalo, M.; Qian, W.; Portenier, I. \& Waltimo, T. Effects of dentin on the antimicrobial properties of endodontic medicaments. J. Endod., 33(8):917-25, 2007.

Kakehashi, S.; Stanley, H. R. \& Fitzgerald, R. J. The effects of surgical exposures of dental pulps in germ-free and conventional laboratory rats. Oral Surg. Oral Med. Oral Pathol., 20(3):340-9, 1965.

Macedo, R. G.; Herrero, N. P.; Wesselink, P.; Versluis, M. \& van der Sluis, L. Influence of the dentinal wall on the $\mathrm{pH}$ of sodium hypochlorite during root canal irrigation. J. Endod., 40(7):10058, 2014.

Macedo, R. G.; Wesselink, P. R.; Zaccheo, F.; Fanali, D. \& Van Der Sluis, L. W. Reaction rate of $\mathrm{NaOCl}$ in contact with bovine dentine: effect of activation, exposure time, concentration and $\mathrm{pH}$. Int. Endod. J., 43(12):1108-15, 2015.

Morgental, R. D.; Singh, A.; Sappal, H.; Kopper, P. M.; Vier-Pelisser, F. V. \& Peters, O. A. Dentin inhibits the antibacterial effect of new and conventional endodontic irrigants. J. Endod., 39(3):406-10, 2013.

Perez, F.; Calas, P. \& Rochd, T. Effect of dentin treatment on in vitro root tubule bacterial invasion. Oral Surg. Oral Med. Oral Pathol. Oral Radiol. Endod., 82(4):446-51, 1996.

Portenier, I.; Haapasalo, H.; Ørstavik, D.; Yamauchi, M. \& Haapasalo, M. Inactivation of the antibacterial activity of iodine potassium iodide and chlorhexidine digluconate against Enterococcus faecalis by dentin, dentin matrix, type-I collagen, and heat-killed microbial whole cells. J. Endod., 28(9):634-7, 2002.

Portenier, I.; Waltimo, T.; Ørstavik, D. \& Haapasalo, M. Killing of Enterococcus faecalis by MTAD and chlorhexidine digluconate with or without cetrimide in the presence or absence of dentine powder or BSA. J. Endod., 32(2):138-41, 2006.

Stuart, C. H.; Schwartz, S. A.; Beeson, T. J. \& Owatz, C. B. Enterococcus faecalis: its role in root canal treatment failure and current concepts in retreatment. J. Endod., 32(2):93-8, 2006.
White, J. M.; Goodis, H. E.; Marshall, S. J. \& Marshall, G. W. Sterilization of teeth by gamma radiation. J. Dent. Res., 73(9):1560-7, 1994

Zehnder, M. Root canal irrigants. J. Endod., 32(5):389-98, 2015.

Dirección para correspondencia:

Aurealuz Morales Guevara

Docente de la cátedra de Endodoncia

Universidad Católica Santo Toribio de Mogrovejo

Chiclayo

PERÚ

Email: aurimg@hotmail.com

Recibido : 13-06-2019

Aceptado: $10-02-2020$ 